\title{
RANCANG BANGUN APLIKASI SISTEM PAKAR UNTUK KONSULTASI PERILAKU SISWA DI SEKOLAH MENGGUNAKAN METODE FORWARD CHAINING
}

\author{
Arif Harjanto \\ Fakultas Teknik, Program Studi Teknik Elektro \\ Universitas Mulawarman \\ Email: arif.harjanto@ft.unmul.ac.id \\ Sri Karnila \\ Fakultas Ilmu Komputer, Program Studi Sistem Informasi \\ Institut Informatika dan Bisnis Darmajaya \\ Email: srikarnila_dj@darmajaya.ac.id \\ Fajar Nugraha \\ Fakultas Teknik, Program Studi Sistem Informasi \\ Universitas Muria Kudus \\ Email: fajar.nugraha@umk.ac.id
}

\begin{abstract}
ABSTRAK
Jurnal ini menghasilkan Rancang bangun yang di fasilitasi sebuah Program sistem pakar bermanfaat untuk mengkonsultasi perilaku pada siswa dan digunakan mengetahui strategi penanganan dalam keputusan yang harus dilakukan oleh guru bimbingan konseling di sekolah guna menangani perilaku siswa. Pembuatan aplikasi ini peneliti menggunakan tools MySQL sebagai database dan untuk Bahasa pemrograman mengunakan PHP yang ditulis dengan aplikasi Adobe Dreamweaver. Sistem pakar menggunakan forward chaining melalui penyesuain dan dan kebutuhan proses. Berdasarkan hasil konsultasi maka dapat disimpulkan bahwa konseling Sistem Pakar Konsultasi Perilaku Siswa ini sudah sesuai dengan tujuannya yaitu dapat memudahkan pengguna yaitu guru bimbingan konseling dalam mengkonsultasi perilaku siswa dan memberikan solusi sebagai hasil konsultasi untuk penanganan dari permasalahan siswa. pengujian program yang di berikan kepada guru didapatkan nilai presentase sebesar $89,60 \%$ dengan kategori sangat baik
\end{abstract}

Kata kunci: sistem pakar; konsultasi perilaku siswa; forward chaining.

\begin{abstract}
This journal resulted in the Design of a facilitation of an expert system program useful for consulting behavior in students and used to know the strategy of handling in decisions that should be done by teachers counseling guidance in schools to handle student behavior. Making this application researchers using MySQL tools as a database and for programming language using PHP written with Adobe Dreamweaver application. Expert systems use forward chaining through customization and and process requirements. Based on the results of the consultation it can be concluded that the counseling Expert System Consultation Student Behavior is already in accordance with its purpose is to facilitate the user is a counseling teacher in consulting student behavior and provide solutions as a result of consultation for the handling of student problems. testing the program given to the teacher obtained a percentage value of $89.60 \%$ with very good category
\end{abstract}

Keywords: expert system; consultation student behavior; forward chaining.

\section{PENDAHULUAN}

Kemajuan teknologi komputer yang pesat saat ini, sangat membantu manusia dalam segala bidang. Tidak terkecuali juga dalam bidang sistem pakar. Dunia pendidikan dewasa ini menghadapi berbagai masalah yang sangat kompleks yang perlu mendapatkan perhatian [1]. Masalah-masalah tersebut antara lain perubahan kurikulum sehingga sekolah kurang siap dalam melaksanakan proses pembelajaran, keadaan guru yang kurang memenuhi syarat dari segi tingkat pendidikan, fasilitas sekolah yang tidak lengkap maupun masalah kesiswaan yang menyebabkan menurunnya tata krama sosial dan etika moral dalam praktek kehidupan sekolah yang mengakibatkan sejumlah peristiwa negatif yang amat merisaukan 
masyarakat. Menurut guru bimbingan konseling Semakin maraknya berbagai penyimpangan norma kehidupan agama dan sosial kemasyarakatan yang terwujud dalam bentuk penyimpangan pada siswa [2] seperti 1. kurang hormat kepada guru. Perilaku ini tampak dalam hubungan siswaguru di mana siswa sering acuh tak acuh terhadap keberadaan guru dan sekolah. 2. Kurang disiplin terhadap waktu dan tidak mengindahkan peraturan. Siswa masih sering terlambat masuk kelas, membolos, tidak memakai seragam dengan lengkap, dan menggunakan model baju yang tidak sesuai ketentuan dan membawa senjata tajam. 3. Kurang memelihara keindahan dan kebersihan lingkungan. Perilaku ini tampak dengan adanya perbuatan mencorat-coret dinding atau kelas, dan membuang sampah seenaknya. 4. Perkelahian antar pelajar, sering terjadi perkelahian antar siswa satu sekolah bahkan perkelahian antar sekolah lain. 5. Merokok di area sekolah pada jam istirahat. 6. Berbuat asusila, seperti adanya siswa putra yang mengganggu siswa putri dan melakukan perbuatan asusila di lingkungan sekolah. Dari beberapa penyimpangan tersebut saat ini cenderung pada kategori melanggar tata tertib. Sehingga masalah ini bila tidak segera diatasi akan semakin mempengaruhi proses belajar mengajar khususnya. [3] [4].

Sistem pakar dapat digunakan untuk membuat sebuah perangkat yang digunakan dalam mengevaluasi psikologi siswa sehingga dapat memberikan gambaran keunikkan atau karakteristik kepribadian individu dan potensi diri yang dimiliki. Analisi tersebut dapat berdasarkan pemahaman kebutuhan dari masingmasing institusi pendidikan. Dari penelitian ini juga dapat diketahui bahwa institusi pendidikan memiliki tingkat kebutuhan yang berbeda beda dalam melakukan evaluasi terhadap psikologi siswa [5].

Dari latar belakang dan analisa tersebut sebuah sekolah membutuhkan sebuah sistem pakar sebagai solusi yang dapat digunakan untuk mengkonsultasi perilaku siswa. Sitem pakar ini di buat sebagai interface atau alat bantu konsultasi perilaku pada siswa melalui media aplikasi berbasis web kepada guru, sehingga efisiensi waktu untuk penanganan lebih lanjut terhadap masalah siswa tersebut dan dapat dengan cepat dilakukan tindakan. Manfaat dari sistem pakar ini tidak hanya membantu guru BK (Bimbingan Konseling) tetapi juga selain guru BK. Dengan dikembangkan sistem konsultasi berbasis sistem pakar ini, pihak sekolah baik guru BK ataupun bukan mengetahui permsayalahan yang dihadapi siswa, mengetahui strategi untuk menanggani permasaalahan siswa tersebut dan melakukan tindakan cepat dalam memberikan solusi.

\section{METODOLOGI PENELITIAN}

Adapun metodologi yang digunakan dalam penelitian ini melalui beberapa yaitu :

\subsection{Tahap Pengumpulan Data}

a. Metode Observasi

Melakukan peninjauan atau pengamatan secara langsung kelapangan dengan cara mengumpulkan data, informasi, dan mempelajari catatan serta dokumen yang terkait permasalahan yang sering dilakukan siswa di sekolah.

b. Metode Wawancara

Wawancara yang dilakukan oleh peneliti adalah secara langsung kepada pakar psikologi pendidikan yaitu guru bimbingan konseling untuk memperoleh informasi tentang perilaku yang dialami siswa

c. Kuesioner

Kuesioner digunakan untuk memperoleh data pegujian aplikasi sistem pakar untuk konsultasi perilaku siswa.

\subsection{Tahap Pengembangan Sistem}

Tahap pengembangan sistem aplikasi sistem pakar untuk konsultasi perilaku siswa di sekolah menggunakan metode forward chaining ini mengimplementasikan metode pengembangan sistem model Waterfall yang mempunyai tahapan meliputi analisa kebutuhan, desain sistem, kode program serta pengujuan program (gambar 1). Pemodelan Waterfall merupakan metode pengembangan sistem yang sering digunakan oleh para pengembang sistem dengan tahap pengembangan sistem yang terstruktur.

a. Analisa Kebutuhan

Pada tahap ini, peneliti, melakukan analisis terhadap solusi dari perilaku siswa serta melakukan wawancara terhadap guru bimbingan konseling.

b. Desain Sistem

Desain sistem adalah proses yang fokus pada desain pembuatan program Aplikasi Sistem Pakar Untuk Konsultasi Perilaku termasuk struktur data, arsitektur perangkat lunak, representasi antar muka, dan prosedur pengkodean. Tahap ini mentranslasi kebutuhan perangkat lunak dari tahap 
analisis kebutuhan ke representasi desain agar dapat diimplementasikan menjadi program yang sesuai dengan yang diharapkan.

c. Kode Program

Pada tahap ini adalah urutan proses pembuatan dari Aplikasi Sistem Pakar Untuk KonsultasiPerilaku. tahap ini dimulai dari pembuatan database yang menggunakan $M y S Q L$ kemudian dibuat desain tampilan menu dan form-form input sesuai dengan kebutuhan Aplikasi Sistem Pakar Untuk Konsultasi Perilaku, dilanjutkan dengan memasukan coding program sesuai dengan form yang telah dibuat menggunakan bahasa pemrograman PHP yang ditulis menggunakan aplikasi Adobe Dreamweaver CC 2015 16.1.2 untuk membangun Aplikasi Sistem Pakar Untuk Konsultasi Perilaku ini.

d. Pengujian Program.

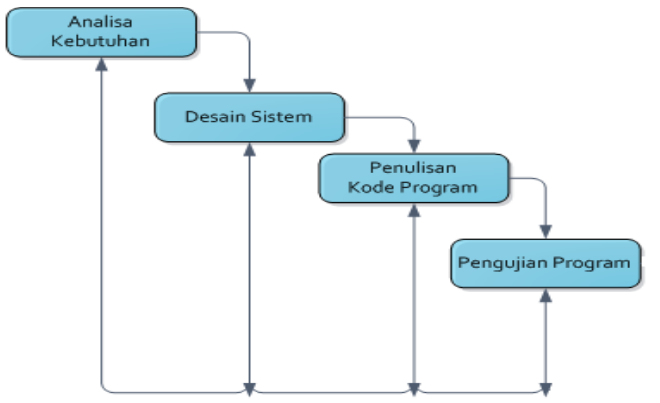

Gambar 1. Diagram Alir Penelitian Model Waterfall

\section{HASIL DAN PEMBAHASAN}

Alur proses penanganan untuk pelanggaran siswa ini menjelaskan tentang proses yang dilakukan untuk penanganan bagi siswa yang melakukan pelanggaran. Adapun alur proses penanganan untuk pelanggaran siswa dijelaskan pada gambar 2.

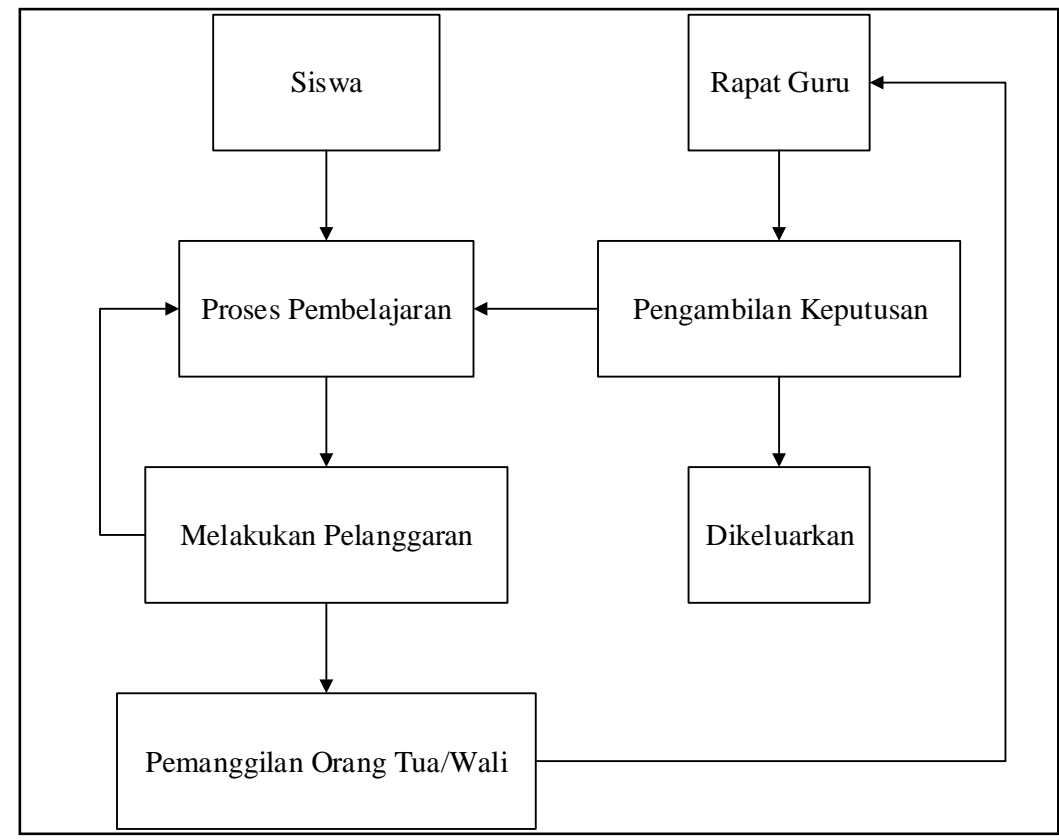

Gambar 2. Alur Proses Penanganan Untuk Pelanggaran Siswa

\subsection{Sistem Yang Berjalan}

Dari analisa sistem yang berjalan dapat diketahui permasyalahan yang terjadi saat ini yaitu belum adanya sistem pakar sebagai alat bantu konsultasi siswa dan tindakan penyelesaian. Berikut adalah Flowchart sebagai penggambaran secara grafis dari langkah-langkah prosedur dari sistem pakar program. Pada bagian ini akan dijelaskan langkah-langkah dalam menjalankan aplikasi sistem pakar konsultasi perilaku siswa yang dibangun di jelaskan pada gambar 3. 


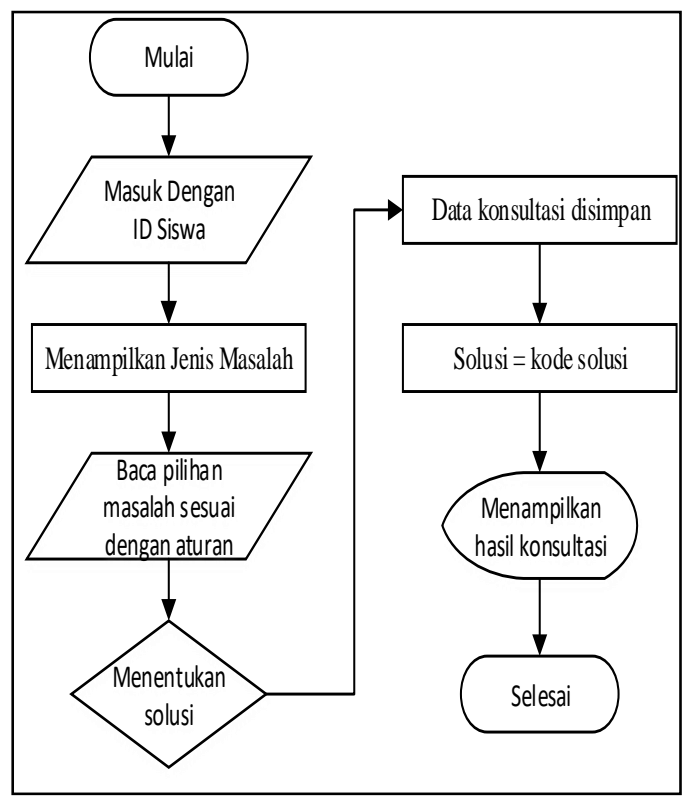

Gambar 3. Flowchart Sistem

\subsection{Context Diagram}

Gambaran sistem secara umum di jelaskan dalam diagram konteks yang menjelaskan hubungan sistem dengan lingkungan sistem. Terdapat dua entitas yang terhubung langsung dengan sistem yaitu USER dan PAKAR seperti pada gambar 4.

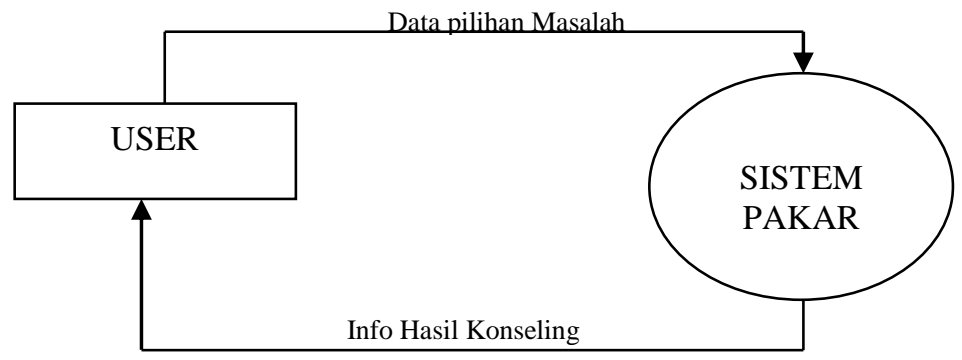

Gambar 4. Context Diagram

\subsection{Data Flow Diagram}

Gambaran sistem pakar di jelaskan dalam Data Flow Diagram (DFD) yaitu diagram alir yang dipresentasikan dalam bentuk lambang - lambang tertentu yang menunjukan aliran data, proses, dan tempat penyimpanan data pada sistem.

a. DFD Level 1

Berikut adalah DFD Level 1, yaitu rincian turunan dari diagram konteks. Dapat dilihat pada gambar 5 .

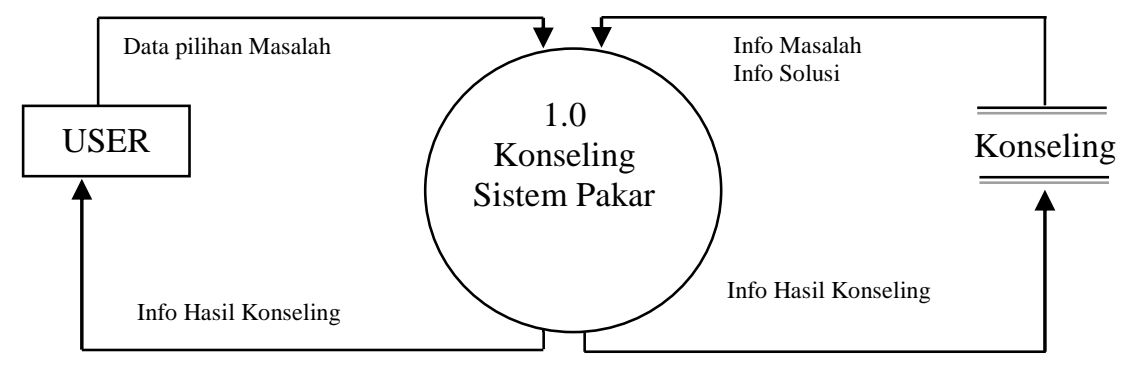

Gambar 5. DFD Level 1 
b. DF'D Level 2

Gambar 6 berikut adalah DFD level 2 proses konseling.

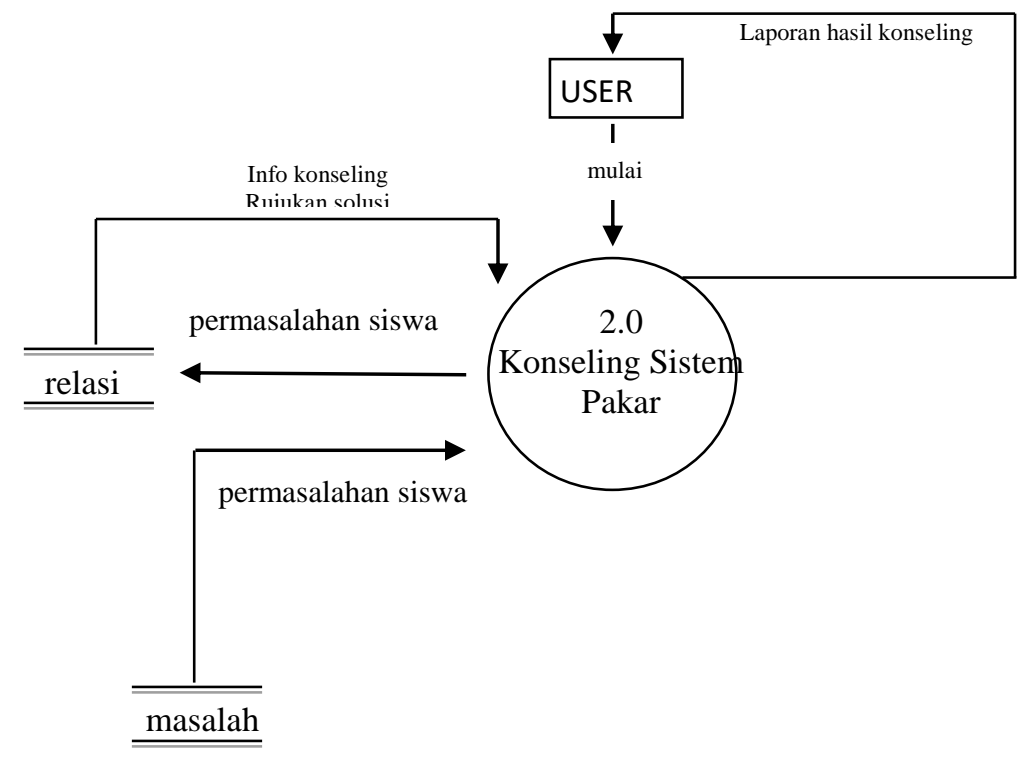

Gambar 6. DFD Level 2

\subsection{Entity Relationship Diagram (ERD)}

Entity Relationship Diagram (ERD) adalah suatu model untuk menjelaskan hubungan antar data dalam basis data berdasarkan objek-objek dasar data yang mempunyai hubungan antar relasi. ERD pada sistem pakar konsultasi perilaku siswa dapat dilihat pada gambar 7 .

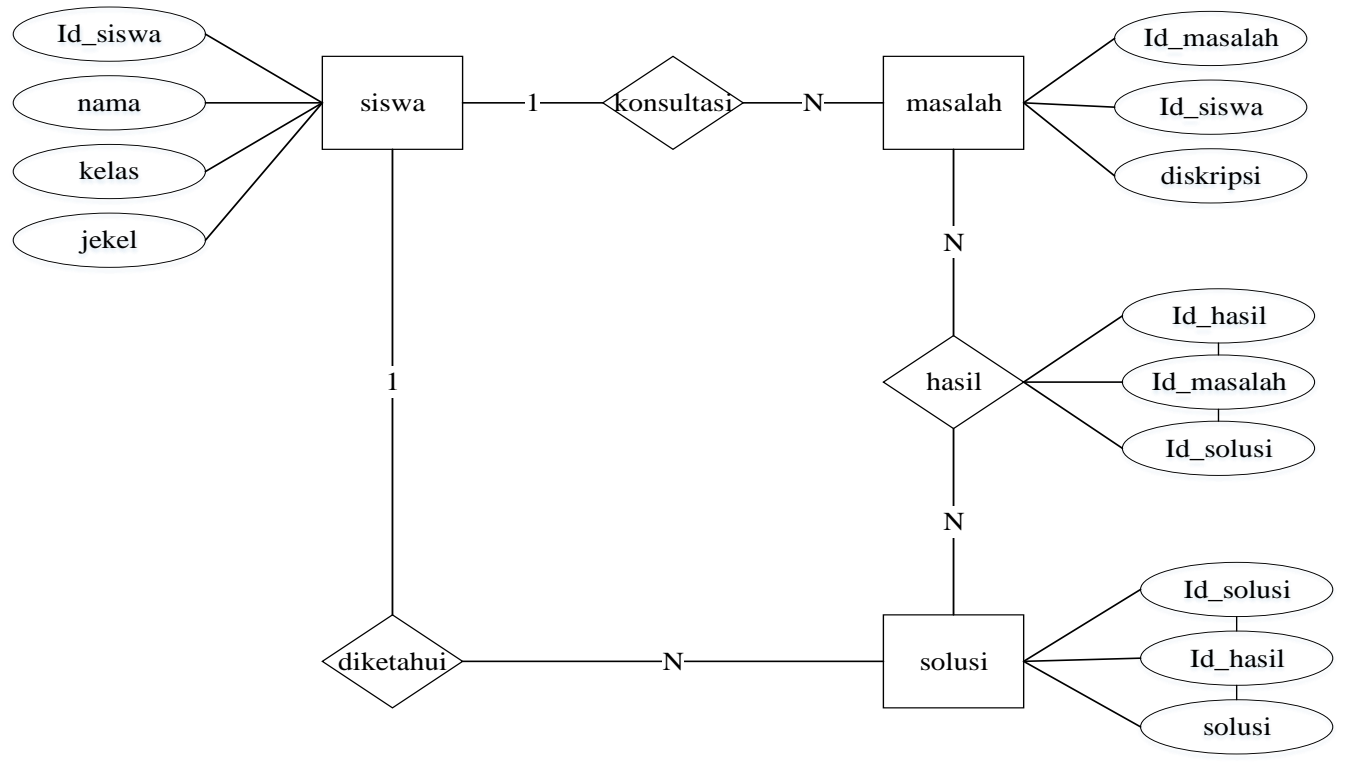

Gambar 7. Entity Relationship Diagram (ERD)

\subsection{Pohon Pelacakan Dengan Metode Forward Chaining}

Metode Forward Chaining adalah metode pelacakan kedepan yang dimulai dengan menghimpun suatu informasi yang telah ada untuk kemudian dilakukan penggabungan rule sehingga akan menghasilkan suatu kesimpulan atau tujuan yang dapat digunakan sebagai acuan [6]. Pada gambar 8 . dapat dilihat bahwa P01 merupakan jenis masalah pertama pada sistem. Bila memilih P01, maka akan 
ditemukan S01 sebagai solusi dan seterusnya jika memilih jenis masalah selanjutnya sebagai masalah yang akan dikonsultasikan.

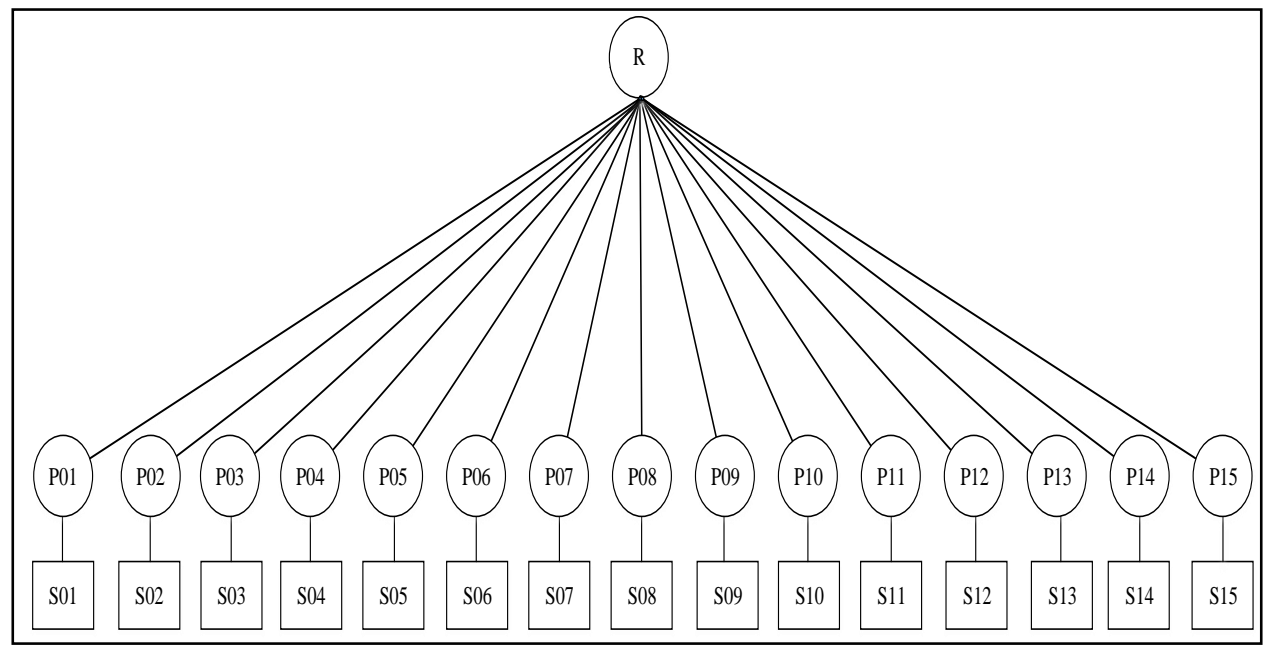

Gambar 8. Pohon Pelacakan Forward Chaining

\subsection{Pohon Keputusan Dengan Metode Forward Chaining}

Pohon keputusan digunakan sebagai dasar membangun kumpulan aturan yang diperlukan untuk menghasilkan solusi berdasarkan masalah yang ada.Pohon keputusan ini dapat berkembang ketika ada penambahan data masalah maupun solusi baru. Dapat dilihat pada gambar 9.

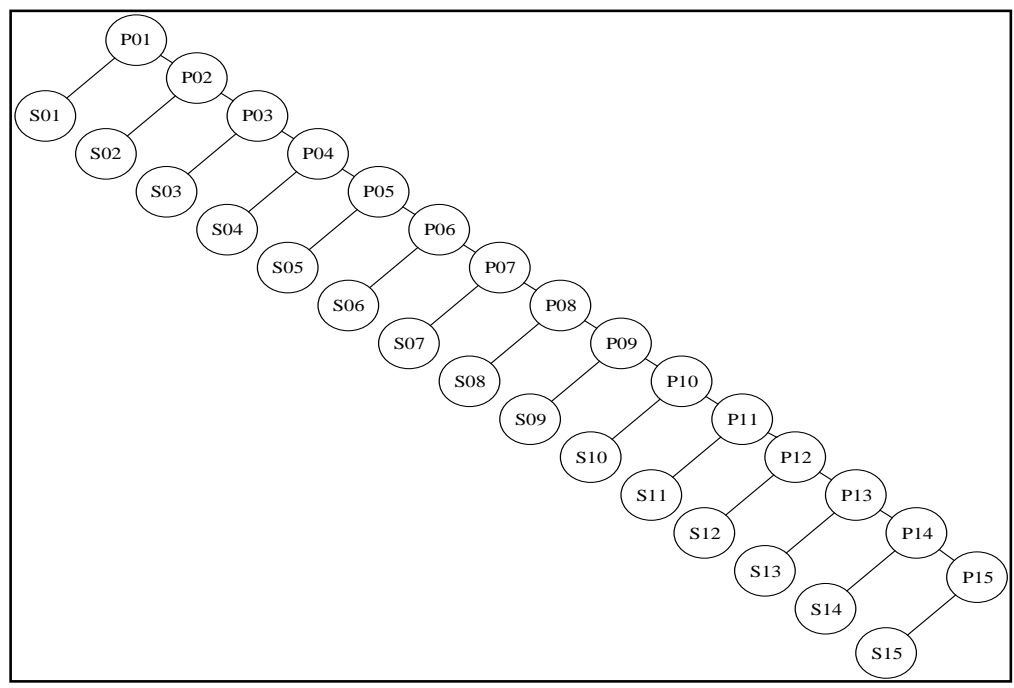

Gambar 9. Pohon Keputusan Forward Chaining

\section{IMPLEMENTASI PROGRAM}

Implementasi antar muka menggambarkan tampilan dari aplikasi yang dibangun yaitu implementasi antar muka sistem pakar analisis perilaku siswa. Gambar 10, 11 berikut ini adalah implementasi antar muka dari aplikasi yang dibuat: 


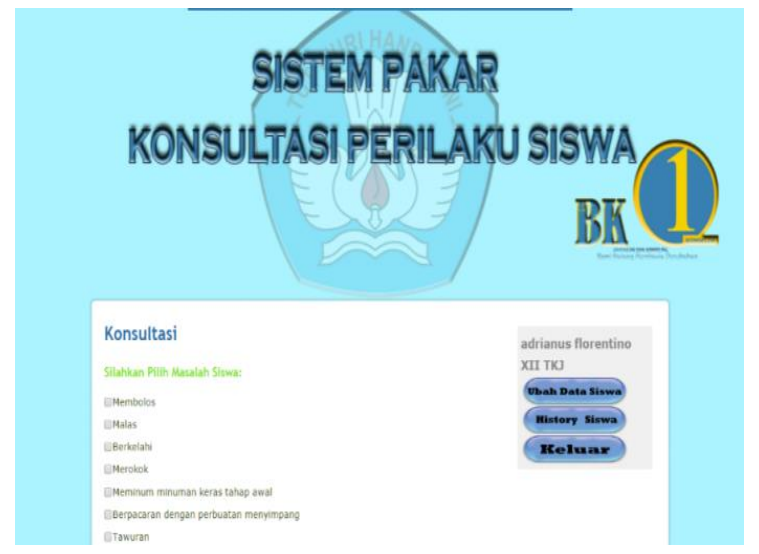

Gambar 10. Halaman Konsultasi

Pada tampilan halaman konsultasi tersebut, user dapat memilih masalah yang ingin di konsultasikan, minimal satu pilihan masalah, setelah itu menekan tombol proses untuk mengetahui solusi dari permasalahan yang di pilih. Apabila user tidak memilih satupun masalah maka solusi tidak akan dapat diproses oleh sistem

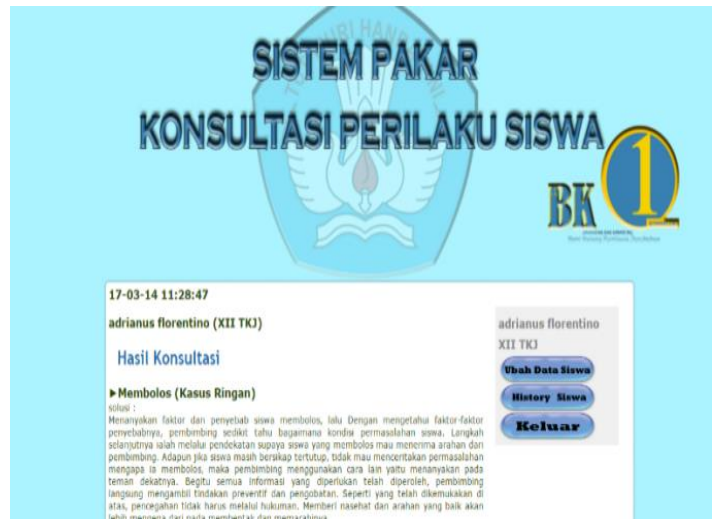

Gambar 11. Halaman Hasil Konsultasi

Pada halaman hasil konsultasi ini menampilkan hasil konsultasi dari masalah yang di pilih user. Hasil konsultasi ini akan tersimpan dan terhubung langsung dengan halaman history siswa dan halaman history kelas.

Form daftar pada gambar 12 digunakan untuk mendaftarkan siswa baru dengan mengisi data diri dari siswa tersebut diantaranya adalah nama, id siswa, jenis kelamin dan kelas. Siswa yang sudah terdaftar otomatis datanya akan tersimpan dan ditampilkan pada halaman info data siswa.

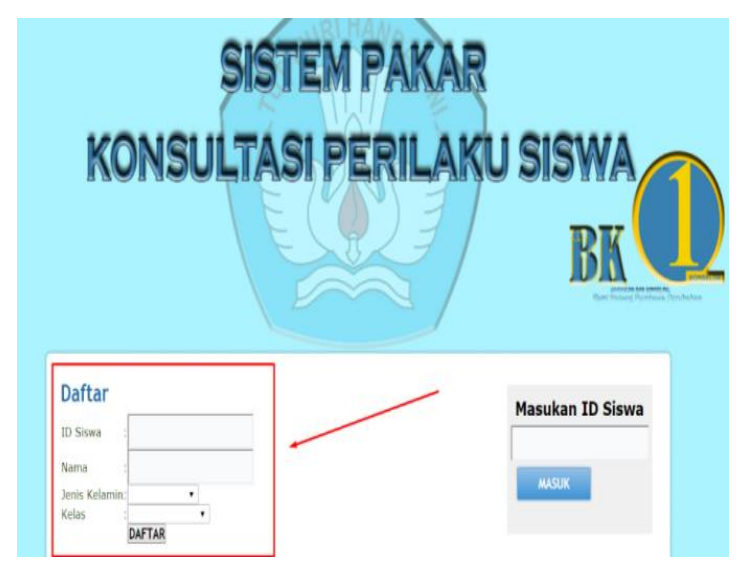

Gambar 12. Form Daftar 
Dari halaman history siswa pada gambar 13 ini dapat memberikan informasi atau menampilkan data dari hasil konsultasi siswa yang pernah dilakukan dilengkapi dengan waktu konsultasi. Data yang tampil pada halaman ini hanya meliputi data hasil konsultasi dari id_siswa yang sedang aktif.

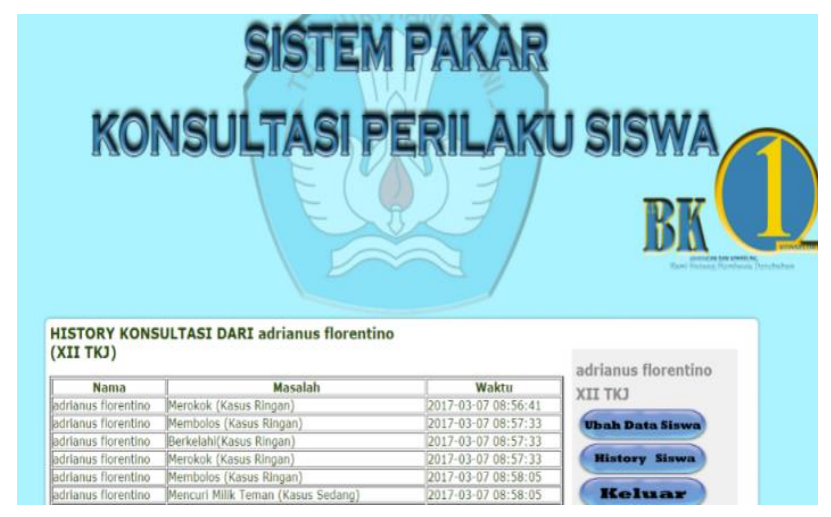

Gambar 13. Halaman History

\section{KESIMPULAN}

Berdasarkan perancangan dan implementasi sistem pakar untuk konsultasi perilaku siswa dapat disimpulkan sebagai berikut :

a) Mengembangkan aplikasi sistem pakar untuk konsultasi perilaku siswa menggunakan Bahasa pemrograman PHP, serta MySQL sebagai basis datanya. Agar hasil diagnosa dapat akurat perancang menggunakan metode "Forward Chaining".

b) Sistem pakar ini dapat digunakan untuk mengkonsultasikan jenis masalah yang dialami siswa berdasarkan solusi yang berasal dari pakar psikologi bidang pendidikan dan studi literatur.

c) Sistem pakar ini dapat menghasilkan solusi yang dapat digunakan guru dalam pengambilan keputusan untuk menangani perilaku siswa.

\section{DAFTAR PUSTAKA}

[1] Daryanto and M. Farid, Bimbingan Konseling - Panduan Guru BK dan Guru Umum. Yogyakarta: Gava Media, 2016.

[2] S. Risaldy and M. H. Idris, Bimbingan dan Konseling - Implementasi pada Pendidikan Anak Usia Dini. Jakarta: Luxima Metro Media, 2014.

[3] B. Walgito, Pengantar Psikologi Umum. Yogyakarta: Andi, 2004.

[4] Suryabrata and Sumadi, Psikologi Pendidikan. Jakarta: Rajawali, 1990.

[5] H. Destiana and S. Suleha, "Sistem Pakar Evaluasi Psikologis Remaja Pada Lembaga Indonesia Creative Centre Jakarta," Paradigma, vol. XVIII, no. 2, pp. 37-48, 2016.

[6] T. Wahyuni, "Sistem Pakar Untuk Mengidentifikasi Masalah Psikologi Remaja Menggunakan Metode Inferensi Forward Chaining Berbasis Android," J-Ensitec, vol. 02, no. 02, pp. 25-31, 2016. 